\title{
Knowledge, Attitude and Practice regarding Tuberculosis among Diabetic Patients
}

\author{
Hossain $\mathrm{MD}^{\mathrm{a}^{*}}$, Afroz $\mathrm{F}^{\mathrm{b}^{*}}$, Ahmed JU' $\mathrm{J}^{\mathrm{c}}$, Amin $\mathrm{MK}^{\mathrm{d}}$, Quddus $\mathrm{SMR}^{\mathrm{e}}$, Islam $\mathrm{S}^{\mathrm{f}}$
}

\begin{abstract}
Background: Tuberculosis (TB) is a major public health problem in Bangladesh. This study aimed to evaluate the current status of the knowledge, attitude, and health-seeking practice regarding TB amongst diabetic patients.

Methods: This cross-sectional study was done in the Pulmonology OPD of Department of Internal Medicine, BIRDEM, 750 bedded Specialized Diabetic Tertiary Care hospital, Dhaka, Bangladesh from January to December 2015.

Results: Out of 420 subjects (mean \pm SD, age $51 \pm 12$ years), 51\% were male. Regarding educational status, $42 \%$ had primary and $34 \%$ had secondary education, while 12\% graduated and $12 \%$ never attended school. More than half of the subjects belonged to the lower-middle income group. The proportion of poor, average and good score for knowledge were $19 \%, 66 \%$ and $15 \%$, attitude $6 \%, 42 \%$ and $52 \%$ and for practice $11 \%, 82 \%$ and $7 \%$ respectively.
\end{abstract}

Conclusion: Co-ordinated educational campaign with prioritized focus for poorer and less educated people needs to be considered for reducing tuberculosis transmission and better outcome with special attention to diabetic population.

Keywords: Tuberculosis, diabetes mellitus, knowledge, attitude and practice of TB patients

(BIRDEM Med J 2017; 7(2): 127-131)

Author Information

a. Dr. Md. Delwar Hossain, MD (Chest), Associate Professor, Internal Medicine, Ibrahim Medical College and BIRDEM General Hospital, Dhaka, Bangladesh

b. Dr. Farhana Afroz, FCPS (Medicine), Registrar, Internal Medicine, Ibrahim Medical College and BIRDEM General Hospital, Dhaka, Bangladesh

c. Dr. Jamal Uddin Ahmed, FCPS (Medicine), Assistant Professor, Internal Medicine, Ibrahim Medical College and BIRDEM General Hospital, Dhaka, Bangladesh

d. Dr. Md Kamrul Amin, Assistant Professor, Community Medicine, Institute of Health Technology, Rajshahi, Bangladesh

e. Dr. Sharif Mohammad Ruhul Quddus, Medical Officer, Neurology, BIRDEM General Hospital, Dhaka, Bangladesh

f. Shafiqul Islam, Program manager, BADAS-USAID Challenge TB Project, Bangladesh.

* Both the authors have equal contribution in this study. So, they should be considered as first authors.

Address of correspondence: Dr. Md. Delwar Hossain, MD (Chest), Associate Professor, Internal Medicine, BIRDEM General Hospital. Email: delwarhschest@yahoo.com, lubna 0408@gmail.com

Received: October 28, 2016

Accepted: February 28, 2017

\section{Introduction}

Bangladesh is one of the highest tuberculosis (TB) burden countries in the world, ranking $7^{\text {th }}$ among 22 countries where the number of people with diabetes is also rising rapidly. According to World Health Organization (WHO) report, the current prevalence and incidence of TB in Bangladesh is 404 and 227 per 100,000 population per year respectively. ${ }^{1}$ Furthermore, people with diabetes are around 2.5 times more likely to develop tuberculosis and about $10 \%$ of TB cases globally are linked to diabetes. ${ }^{2,3}$ This huge burden of tuberculosis and diabetes must be taken into account and an effective step should be taken to reduce these burdens. ${ }^{4}$ Assessment of knowledge, attitude, and practice regarding tuberculosis is essential to plan, implement, and evaluate advocacy, communication, and social mobilization work. ${ }^{5}$ It may improve the case detection rate. Besides, the directly observed therapy short course (DOTS) effectiveness might be determined by the patients' health-seeking behaviors, which is 
related to patients' demographic characteristics, knowledge of TB, health education, and traditional beliefs. These are also believed to have a crucial impact on treatment compliance and treatment success rate. ${ }^{\mathbf{6}, 7}$ The aims of our study were to assess the current status of knowledge, attitude, and practice regarding tuberculosis among diabetic patients and to relate their selected sociodemographic characteristics and education status with their knowledge of TB.

\section{Methods}

This cross-sectional study was done in Bangladesh Institute of Research and Rehabilitation in Diabetes, Endocrine and Metabolic Disorders (BIRDEM) General Hospital, Dhaka, Bangladesh from January to December 2015. A total of 420 adult (18-70 years) (male 213 and female 207) diabetic patients were selected purposively. Data were collected by face to face interview and in pre-designed, semi-structured questionnaire. Monthly family income was categorized by USD as low $(\leq \$ 87)$, lower-middle (\$87-\$312) and upper-middle group (\$312-\$937). Questions evaluating attitude regarding tuberculosis were associated with the categorical response 'agree', 'neither agree nor disagree' and 'disagree' by asking. Knowledge, attitude and practice were categorized by pre-defined scores. Three categories were defined on the basis of the score obtained by each participant: Poor $(<$ Mean $-1 \mathrm{SD})$; Average (Mean $\pm 1 \mathrm{SD}$ ) and Good (>Mean $+1 \mathrm{SD}$ ). Each correct and incorrect response of knowledge and practice part of the questionnaire was assigned a score of ' 1 ', and ' 0 ' respectively. Data were analyzed by SPSS version 20. Diabetic subjects who were mentally and physically fit to answer the questions and willing to participate, were included in the study.

\section{Results}

Total patients were 420 with a mean age of $51 \pm 12$ years and male predominance $(213,51 \%)$. Regarding educational status, $42 \%$ had primary and $34 \%$ had secondary and higher secondary education, while $12 \%$ graduated and $12 \%$ never attended school. Over twothird $(290,72 \%)$ of the respondents belonged to the low-income group, one-fifth (20\%) belonged to the lower-middle-income and rest (8\%) belonged to the upper-middle income group. Higher proportion of the subject $(290,72 \%)$ lived in nuclear family. Exploring the dwelling pattern of the respondents revealed that
246(61\%) lived in Bricked build while 53 (13\%) lived in Thatched house. Among them 264 (65\%) were sharing same bed room with 2 person while, $76(19 \%)$ were sharing same bed room with 3 persons or more. Of the subjects $253(63 \%), 120(30 \%)$ and $30(7 \%)$ were using gas, firewood and other means (electricity, kerosin, dried cowdung etc) for cooking respectively, while 28 (7\%) did not have a separate kitchen and used to cooked in the same bed room. Twenty eight (5\%) had history of TB in among friends and neighbors. Positive history of smoking was found in $27(6 \%)$. One-third of respondents had past history of tuberculosis and 50 $(13 \%)$ had positive family history of tuberculosis. Nearly $60 \%$ of respondents knew that prolonged cough is a symptom of TB and infectious droplet as the commonest mode of transmission (38\%) (Table I).

Table I. Knowledge about Symptom, Risk factors and Mode of Transmission of Tuberculosis among the study subjects (N-420)

\section{Symptoms of Tuberculosis}

Cough for more than 3 weeks

Blood in sputum

Loss of Appetite

Night sweats with Fever

Weight loss

Don't know

$60(14)$

\section{Risk factors of Tuberculosis}

Indoor air pollution

Malnutrition

Smoking

Diabetes

HIV/AIDS

Over crowding

$70(16)$

\section{Mode of TB Transmission}

Through the air when coughing/ Infectious droplet spread $163(38)$

Through blood

Through hand shake with an infected patient19 (6)

Sexually transmitted 64 (15)

Sharing food with infected person $\quad 59(14)$

Hereditary $2(0.5)$

Don't know 61 (14) 
Most of the patients acquired their knowledge regarding TB from television, other sources are shown in Fig.1. The attitude regarding TB is presented in (Table II). Over half of the subjects responded that distance and scarcity of vehicle as important barrier to avail health care facility (Table III).

Table II. Attitude regarding tuberculosis (N-420)

How serious a problem do you think TB is in your area?

Very serious

Not Very serious

Don't know

Is it shameful to have TB?

Yes

No

If someone has TB will others treat them differently? Yes

No

Table III. Practice regarding tuberculosis (N-420)

If you had TB signs where would you go to get medical service?

$\begin{array}{lc}\text { Family doctor } & 26(6) \\ \text { Pulmonologist } & 51(12) \\ \text { Hospital } & 228(54) \\ \text { Polyclinic } & 14(3) \\ \text { TB cabinet } & 73(17) \\ \text { Don't know } & 47(11)\end{array}$

Hindrance to avail healthcare facility, what is the reason?

Cost

Difficulties with transportation/distance 230 (54)

Do not like attitude of medical workers 51(12)

Overlapping work hours with medical facility working hours

Others

$14(3)$

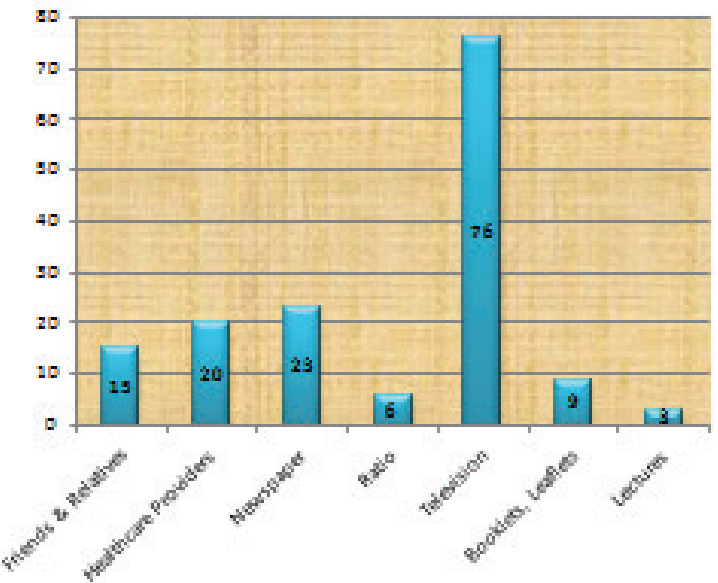

Figure 1. Source of knowledge of tuberculosis among diabetic patients s pwe respondent's opinion

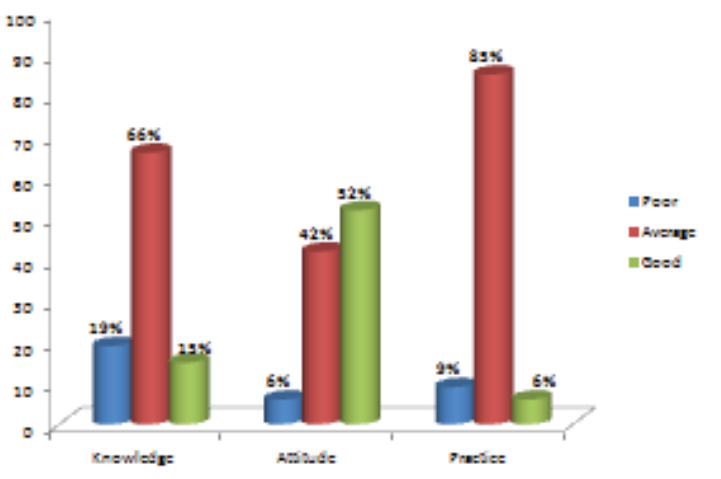

Figure 2. Total knowledge, attitude \& practice score of the study subjects according to different questions on Tuberculosis

The proportion of poor, average and good score for knowledge was $19 \%, 66 \%$, and $15 \%$ attitude $6 \%, 42 \%$, and $52 \%$ and practice $11 \%, 82 \%$ and $7 \%$ resesctively (Fig-2).

\section{Discussion}

In a community with low levels of awareness about the cause, mode of transmission and preventive methods, the spreading of TB could be high. Several studies done in Ethiopia and Manila explained that the majority of respondents heard about TB from television, newspaper, health workers and personal experience for the first time, this study also reported similar findings. This indicates that mass media, health workers and personal experience 
were acting as a successful means of disseminating information about $\mathrm{TB}$ and it was a promising means for better detection of TB cases. ${ }^{8}$

In most of the TB control efforts, including clinical aspects of the diseases receive more attention than the human aspects. There is a growing realization that the psychosocial suffering experienced by TB patients and their families needs more attention. Therefore it has become clear that problems in case detection and caseholding are not solved by a clinical approach alone, but there is a need for community participation to support the efforts of health care workers, While giving special attention to the gender aspects of TB. As community involvement is crucial for any successful TB control programme, several studies have been performed to identify knowledge, perceptions and practices of the population regarding the occurrence, transmission, treatment and control of TB.On the other hand, inefficient case-finding is an important obstacle to successful control of TB. Patients who are involved in several different health care encounters may account for delayed case-finding. Case studies illustrate the rationale for health-seeking and explain delayed initiation of appropriate approaches to health communication for improved control of TB. Certain reports also suggest that improved interpersonal skills of health centre staff and coordination between private doctors and health centres may substantially improve services for TB patients. This study revealed that the majority of respondents feared, stigmatized, and worried if they had TB. This finding was similar to other studies conducted in Ethiopia, Tanzania, and Norway. ${ }^{9}$ Furthermore, this finding indicated the need to strengthen health education activities about TB. Some studies depicted that educational background and residence of respondents was important determinants of TB knowledge. This study also found that a low level of knowledge score was significantly associated with illiterate and rural people. ${ }^{9,10}$

It would be better to establish an appropriate control measure such as establishing proper information, education, and a communication pathway that indicate the level of severity of the disease. In addition, creating proper awareness about its cause, transmission, prevention, and availability of public service are very essential.

Long and others in China and in Ethiopia showed that low awareness, poor knowledge, and low financial capacity to pay for care and diagnoses were factors contributing to delayed health seeking. ${ }^{11}$ Our study also found that a majority of respondents delayed in seeking care because of cost and difficulties of transportation. As a result, improving knowledge and practice about symptoms, risk factors, complication and prevention of TB will be more effective in reducing its burden. The extent of not adhering to recommended management for TB varies in different ethnicities and communities of Bangladesh. So correct knowledge and positive perception of the patient toward TB and its management is a prerequisite for them to seek early health care.

From open-ended questions the majority of the respondents worried that the disease may be transmitted to their family. They also worried that the disease might not be curable and that society may stigmatize them. In addition, they felt sad because they cannot work properly.

Developing countries shoulder most of the burden of diabetes and tuberculosis. ${ }^{12}$ These diseases often coexist. Suboptimal control of diabetes predisposes the patient to tuberculosis, and is one of the common causes of poor response to anti-tubercular treatment. Tuberculosis also affects diabetes by causing hyperglycemia and causing impaired glucose tolerance. Impaired glucose tolerance is one of the major risk factors for developing diabetes. The drugs used to treat tuberculosis (especially rifampicin and isoniazid) interact with oral anti-diabetic drugs and may lead to suboptimal glycemic control. Similarly some of the newer oral anti-diabetic drugs may interact with antituberculosis drugs and lower their efficacy. ${ }^{13}$ Therefore diabetes and tuberculosis interact with each other at multiple levels - each exacerbating the other. Management of patients with concomitant tuberculosis and diabetes differs from that of either disease alone. ${ }^{14}$ Both diseases are major public health problems and link between the two diseases should paid special concern. However, continuous evacuations of such strategies are need of time as it helps policy makers and programme management to frame and re-frame their future plans. Although studies have been carried out by different researchers, in many countries to assess knowledge, attitude and practices of patients on various aspects of DM and TB, but limited hospital based data are available in this respect. ${ }^{15,16,17}$ Correct knowledge and positive perception of the patient toward TB and its management is a prerequisite for them to seek early health care. 


\section{Conclusion}

The overall level of knowledge, attitude and practice regarding tuberculosis was average in Bangladeshi population. This study may provide data for policy makers towards developing plans for the improvement of adult health in Bangladesh. Furthermore, the national TB control program should consider coordinating advocacy, communication, and social mobilization activities on the communities to improve KAP of patients, to reduce misconceptions, and prevent transmission of TB in the community.

\section{Conflict of interest: None}

Declaration: This paper was presented in 27th Annual Conference of the Association of Physician of Bangladesh in Dhaka, 2016.

\section{References}

1. WHO Global Tuberculosis Report. 2015

2. Ottmani S.-E, Murray MB, Jeon CY, Lonnroth K, Barreto $\mathrm{ML}$, Billo $\mathrm{N}$ et al. Consultation meeting on tuberculosis and diabetes mellitus: meeting summary and recommendations. Int J Tuberc Lung Dis 2010; 14 (12): 1513-17.

3. Goldhaber-Fiebert JD, Jeon CY, Cohen T, Murray MB. Diabetes mellitus and tuberculosis in countries with high tuberculosis burdens: individual risks and social determinants. Int J Epidemiol 2011; 40 (2): 417-28.

4. WHO Global Tuberculosis Control: Epidemiology, Strategy, Finances. Geneva: World Health Organization; 2014.

5. Ministry of Health National Tuberculosis Control Program in Bangladesh, Bangladesh: Ministry of Health; 2012.

6. Lawn SD, Afful B, Acheampong JW. Pulmonary tuberculosis: diagnostic delay. Int J Tuberc Lung Dis. 2006; 4:1190-91.

7. Demissie M, Lindtjorn B, Berhane Y. Patient and health service delay in the diagnosis of pulmonary tuberculosis. BMC Public Health. 2009; 2:23.
8. Auer C, Sarol JJ, Tanner M, Weiss M. Health seeking and perceived causes of tuberculosis among patients in Manila. $J$ Trop Med Int Health 2000; 5:648-56.

9. Yimer S, Bjune G, Alene G: Diagnostic and Treatment delay among pulmonary tuberculosis patients in Ethiopia: a cross sectional study. BMC Infect Dis 2005; 5:112.

10. P Blasco, L Bonte, L Frigati, P Humbulet, Martin A, Sizaire V, et al. Medicine Sans Fronti ers (MSF): tuberculosis: practical guide line $5^{\text {th }}$ revised edn on tuberculosis for clinicians, nurses, laboratory technicians and medical auxiliaries, Paris. France 2010, 25:27.

11. Long Q, Li Y, Wang Y, Yue Y, Tang C, Tang S, et al. Barriers to accessing TB diagnosis for rural-to-urban migrants with chronic cough. BMC Health Serv Res. 2008; 8:202.

12. Geneau R, Stuckler D, Stachenko S. Chronic diseases: chronic diseases and development. Raising the priority of preventing chronic diseases: a political process. Lancet 2010; 376: 1689-98

13. Creswell J, Raviglione M, Ottmani S. Tuberculosis and noncommunicable diseases: neglected links and missed opportunities. Eur Respir J 2011; 37:1269-82

14. Dooley KE, Chaisson RE. Tuberculosis and diabetes mellitus: convergence of two epidemics. Lancet Infect Dis 2009; 9: 737-46.

15. Peleg AY, Weerarathna T, McCarthy JS, Davis TME.Common infections in diabetes: pathogenesis,management and relationship to glycaemic control. Diabetes Metab Res Rev 2007; 23:3-13

16. Leung CC, Lam TH, Chan WM. Diabetic control and risk of tuberculosis: a cohort study. Am J Epidemiol 2008;167: 148694.

17. Jeon CY, Murray MB. Diabetes mellitus increases the risk of active tuberculosis: a systematic review of 13 observational studies. PLoS Med 2008; 5:152 